\title{
BIBECHANA
}

\section{Surfactants, its applications and effects on environment}

\author{
S.K. Shah, A. Bhattarai , S. K. Chatterjee* \\ Dept. of Chemistry, Mahendra Morang Adrash Multiple Campus, Biratnagar, Tribhuvan University, Nepal \\ Article history: Received 2 December 2010; Accepted 5 December 2010
}

\begin{abstract}
Surfactant is being considered as a very demandable molecule in the field of chemistry. This paper reviews most important factors especially the uses of surfactants and their effects on environment. Evaluation of surfactants are based on examining the ability of the surfactant to maintain lower interfacial tension between target contaminant and water, satisfying lower CMCs, and sustaining lower sorption and precipitation to target substrate. Surfactant mixtures of anionic and nonionic surfactant are shown to be excellent candidates for robust surfactant cleaners.
\end{abstract}

Keywords: Surfactant, Interfacial tension; Critical micelle Concentration; Anionic surfactant; Nonionic surfactant

\section{Introduction to Surfactants}

Surfactants are amphiphilic molecules having a hydrophilic or water soluble moiety (head group) and a hydrophobic, or water insoluble moiety (tail group). At low concentrations, surfactants exist solely as monomers. The formation of micelles, begins at a specific surfactant concentration termed the critical micelle concentration (CMC), where the physical properties of the solution, such as interfacial tension, electrical conductivity, and light scattering behaviour, often changes abruptly due to the existence of micelles[1]. The CMC concentration corresponds also to the point where the surfactant first shows the lowest surface/interfacial tension [2]. Interfacial tension is the tensile force that exists at the interface of two immiscible liquids. This force arises as a result of mutual dislike of molecules, such as oil and water, on two sides of the interface. If the two liquids are fully miscible with each other, there is no interfacial tension between them. The amphiphilic nature of surfactants, which results from their water-like and oillike components, causes them to accumulate at interfaces and thus reduce the interfacial tension between oil and water. Beyond the $\mathrm{CMC}$, the aqueous monomer concentration will not increase with any further addition of surfactant since the additional surfactant will form micelles. Spherical micelles orient with surfactant hydrophobic tails pointed toward the interior and hydrophilic head point outward to the surface of micelles. This creates the hydrophobic interior of

* Corresponding author: Prof. S. K. Chatterjee, Dept. of Chemistry, Mahendra Morang Adrash Multiple Campus, Biratnagar, Tribhuvan University, Nepal, E-mail: sujeetkumarchatterjee@ yahoo.com, Tel.: +9779842059697 
the micelle within which hydrophobic organic molecules can partition, thus increasing the aqueous solubility of the none-aqueous liquids (NALs) in the solution. This is referred to as micellar solubilization[1]. Therefore, below the CMC, micelles do not form and the surfactant solution does not enhance the solubilization for NALs. Surfactants are classified as ionic and nonionic with varying chemical structures according to their hydrophilic group. For industrial applications, the ionic surfactants are classified based on the charge they carry when dissociated in water at their neutral $\mathrm{pH}$. These classifications are namely anionic, cationic and zwitterionic or amphoteric[1,3]. Surfactants are also classified according to the balance between the hydrophilic and hydrophobic, or lipophilic, portions of the surfactant molecule. A lipophilic substance is one with a high affinity for fatty or organic solvents and it is essentially a hydrophobic substance [4]. Surfactants with a high hydrophile lipophile balance (HLB) number are more soluble in water, and a low HLB indicates the surfactant is more soluble in an organic solvent [5].

\subsection{Surfactants enhanced industries}

Surface-active agents, or surfactants, are widely used in many industrial and commercial products and possessed throughout the world. Surfactants are not only related to soaps and detergents in daily life, they are also in heavy demand for industrial processes requiring colloid stability, metal treatments, mineral flotation, pesticides, oil production, pharmaceutical formulation, emulsion polymerization, and particle growth $[6,7]$.

\subsection{Surfactants created environmental problems}

The broad range of surfactant applications may also cause side effects in the environment and in these industrial processes. The application of surfactants can also produce environmental pollution and raises a series of problems for wastewater treatment plants [8].

The target of surfactant analysis would be twofold: quality assurance for commercial products and pollution control in environment [9]. In assay of surfactant products, the analytical methods should be able to identify surfactants of various types universally in a simple way. In conjunction with pollution control, on the other hand, the techniques to identify and quantify the surfactants released from the surfactant products to the environments would require much lower detection limits at the level of trace analysis $[10,11]$.The constraint of extremely low detection limit is due to huge dilution and biodegradation of the released surfactants in environments. The currently most important uncharged nonionic surfactants, are the branched-chain and, therefore, biodegradation-resistant alkylphenol ethoxylates (APEOs) constituting about $7 \%$ of the world surfactant consumption. The APEOs $\left[\mathrm{C}_{n} \mathrm{H}_{2 n+1}-\mathrm{C}_{6} \mathrm{H}_{4}-\mathrm{O}-\left(\mathrm{CH}_{2} \mathrm{CH}_{2} \mathrm{O}\right) \mathrm{mH}\right]$ are environmentally persistent organic pollutants (POPs) because their biodegradation is very slow and quite often incomplete for a long period of time. Moreover, several of their degradation products and metabolites are more toxic to aquatic organisms than the parent homologs and, therefore, their persistence and showing estrogenicendocrine modulating effects in aquatic organisms is a "hot" issue of major health- and environment-related concern worldwide. Although there is still not enough evidence to support the hypothesis that exposure to endocrine-disrupting chemicals (EDCs) is a global environmental human health problem, the following relevant facts have been established.

Estrogenic activity of domestic sewage treatment work effluents was shown to occur at levels capable of producing biological effects in fish exposed to this water [12].Many of the xenoestrogens, such as the APEOs, and their degradation products, such as the carboxylated metabolites [13,14], enter the aquatic environment by means of discharge from municipal sewage treatment works, industrial effluents and untreated sewage and can occur in effluents and rivers from nanogram to $\mathrm{mg} / \mathrm{L}$ levels [15-17]. 
Although no clearcut evidence of endocrine disruption was demonstrated, a recent study with 4-nonylphenol, a persistent metabolite of APEOs, has indicated that this compound and some of its short-chain polyethoxylates may have toxic effects at environmentally realistic concentrations of $0.01-10 \mathrm{ppb}[18,19]$. As previously mentioned, the results [20] corroborate these findings and their implications.

\subsection{Surfactants used in daily life}

Cationic surface active substances (CSAS) are important class of pollutants of surface waters. CSAS are frequently used as factors against lumping in artificial fertilizers [21], corrosion protectors [22, 23], and as factors delivering softening effect and static control in washing powders and liquids [24-26]. Frequently they are components in cosmetics [27], pharmaceuticals [28], and antiseptic and sanitary products [29]. CSAS exhibit strong bactericidal and fungicidal activity [30-32].

A result of surfactant pollution include the ability of surfactants to increase the solubility of other toxic organic compounds in soils and when adsorbed to sludge that can have a negative impact on sludge dewatering characteristics at municipal water treatment plants. Two suggestions for reducing surfactant pollution include dispensing only the quantity required of the major components for a particular wash cycle or using environmentally friendly detergents [33]. Surfactant mixtures of anionic and nonionic surfactant are shown to be excellent candidates for robust surfactant cleaners.

At present we are working on the solution properties of cationic surfactant i.e. Cetyltrimethylammonium bromide in methanol-water mixture of different percentage composition and also trying to observe the effect on CMC value [34].

\section{Summary}

This review presents the information about surfactants. It has been shown that successful surfactants enhance industries. But some surfactants create the environmental problems. If we use in a proper way, surfactants will be beneficial for daily uses.

\section{References:}

[1] M.J. Rosen, Surfactants and Interfacial Phenomena, 4th Ed., Wiley-Interscience, New York. (2004).

[2] K. Urum and T. Pekdemir, Chemosphere, 57 (2004) 1139.

[3] K. Holmberg, B. Jonsson, B. Kronberg, and B. Lindman, Surfactants and Polymers in Aqueous Solution, 2nd ed. England, John Wiley \& Sons Ltd. (2003).

[4] D. Myers, Surfaces, Interfaces, and Colloids: Principles and Applications, 2nd Edition, New York: Wiley-VCH, John Wiley and Sons (1999).

[5] J. Childs, E. Acosta, J. F. Scamehorn and D. A. Sabatini, J. Energy Resour. Technol., $127(2005) 153$.

[6] P. C. Pavan, E. L. Crepaldi and J. B. Valim, J. Colloid Interface Sci., 229(2000)346.

[7] C. E. Hoeft and R. L. Zollars, J. Colloid Interface Sci., 177(1996)171.

[8] N. Paxeus, Water Res., 30(1996)1115.

[9] T. M. Schmitt, Analysis of Surfactants in Surfactant Science Series: New York, U.S.A., Vol. 40 (1992).

[10] G. G. Ying, Environ. Int., 32(2006) 417.

[11] W. H.Ding, and Y. H. Liao, Anal. Chem, 73( 2001) 36.

[12] E.J. Rutledge, D. Sheahan, C. Desbrow, G.C. Brighty, M. Maldoc and J.P. Sumpter, Environ. Sci. Technol, 32(1998) 1559. 
[13] M. Ahel, E. Mplnar, S. Ibric and W. Giger, Wat. Sci. \& Tech., 42(2000)15.

[14] J.A. Field and R.L. Read, Environ. Sci. Tech., 30 (1996)3544.

[15] L.N. Britton , J. Surfact. Deterg., 1 (1998) 109.

[16] U. Zoller ,Toxic. Environ. Chem., 66(1997) 145.

[17] C.G. Nylor, J.P. Mieure, W.J. Adams, J.A. Weeks , F.J. Castaldi, L.D. Ogle and R.R.Romano, The Alkylphenols and Alkylphenol Ethoxylates - Review, Vol. 1, Washington, D.C., (1998) pp. 32-43.

[18] Z. Billinghurst, A.S Clare, T. Fileman, J. McEvoy, Readman, J. and M.H. Depledge, Mar. Poll. Bull., 36(1998) 833.

[19] S. Jobling, D. Sheahan, A. Osborne, P. Mathiessen and J.P. Sumpter, Envir. Toxicol. Chem., 15 (1996)194.

[20] U. Zoller, I. Plaut and M. Hushan, Wat. Sci. \& Technol., 50 (2004) (In print).

[21] B. Brycki, Antimicrobial activity and other properties of quaternary ammonium salts; Proceedings of III Symposium on Quaternary Ammonium Salts and the Fields of Their Application in Industry, Poznań, (1997) 24-36 (in Polish).

[22] L. H. Huber, JAOCS, 61(1984) 377.

[23] J. Cross, Introduction to cationic surfactants [in]: Cationic Surfactants, Analytical and Biological Evaluation, Marcel Dekker: New York-Basel-Hong Kong (1994).

[24] S. Giol -ando R.A Rapaport., Chemosphere, 30(1995)1067.

[25] J. Pernak et al., Pol. J Chem, 77 (2003)1263.

[26] R. Lagerman et al., JAOCS, 71 (1994)(1)97.

[27] A. K. Reng, SOFW, 4 (1984) 90.

[28] S. Witek Biological activity of quaternary ammonium salts and lysosomotrophic amines; Proceedings of III Symposium on Quaternary Ammonium Salts and the Fields of Their Application in Industry, Poznań, 7(1998) (in Polish).

[29] W. Śliwa, N-substituted piridinium salts; synthesis, properties and application; Academic Edition WSP , Częstochowa, (1996) (in Polish).

[30] J. Pernak , A. Zabielsk, J. Matejuk and E. Urbanik, Holtzfforschung, 52 (1998)249.

[31] A. Skrzypczak et al., Eur. J. Med. Chem., 32 (1997) 661.

[32] A. Zabielska, J. Matejuk, et al., Holzforschung, 58(2004)292.

[33] J. Hack, J. Chem. Technol. Biotechnol., 50(1991) 379.

[34] S.K. Shah, G. S. Srivastav, A.B. Bhattarai and S.K. Chatterjee, J. Nepal Chem. Soc., 24 (2009) 24. 